\title{
Polarisationsmikroskopische Beobachtungen an den roten Borsten von Mysis flexuosa (Müll.)
}

\author{
Von W. J. Schmidt, Zoologisches Institut, Gießen \\ Aus der Biologischen Anstalt Helgoland, List auf Sylt \\ (Mit 5 Abbildungen)
}

\begin{abstract}
Betrachtet man eine lebende Mysis unter dem Greenough'schen Doppelmikroskop im auffallenden Licht, so erweisen sich die Borsten am Rande der Schuppe der II. Antenne und des Außen- und Innenastes des letzten Abdominalfußpaares in ihrem distalen Abschnitt als leicht gefärbt, und zwar die ersten rötlich, die letzten ähnlich, jedoch etwas mehr ins Violette gehend. Unter dem Mikroskop zeigt sich im durchfallenden Licht die Färbung der genannten, in Seewasser befindlichen Teile recht schwach; man erkennt, daß sie hauptsächlich den zarten Haaren zukommt; die im distalen Abschnitt jeder Borste ansitzen, ähnlich einer Federfahne; aber auch die Borstenschäfte selbst sind gefärbt, jedoch nur basal vom befiederten Teil.

Im dunklen Sehfeld des Polarisationsmikroskopes macht sich an der isolierten Schuppe der II. Antenne - diese untersuchte ich hauptsächlich - eine Aufgliederung der Borsten nach der Länge bemerkbar (Abb. 1): ihr proximaler Abschnitt nämlich ist verhältnismäßig stark doppelbrechend, dann folgt mit dem Beginn des Haarbesatzes ein fast isotropes Stück und schließlich der Endabschnitt, der im Ganzen gesehen schwächer doppelbrechend wirkt. Die eingangs genannte Färbung kommt nur dem stark doppelbrechenden Abschnitt zu, in dem distalen Abschnitt dagegen den Haaren.
\end{abstract}

Abb. 2 stellt diese Verhältnisse bei stärkerer Vergrößerung an einem Ausschnitt des Borstenbesatzes dar. Die Doppelbrechung der Chitincuticula ist schwach (und zwar positiv zur Tangente), bleibt über den ganzen Borstenschaft hinweg gleichmäßig und kommt in Abb. 2 durch Einwirken des Brace-Köhler-Kompensators als Schwärzung zur Geltung; in dem mittleren, schwach doppelbrechenden Abschnitt der Borste liegt sie allein vor (vgl. Abb. 2). Die starke Doppelbrechung im basalen Abschnitt der Borsten aber hat nichts mit der cuticularen Hülle zu tun, sondern wird durch eine doppelbrechende Masse im Borstenschaft verursacht, die wie eine Röhre der Cuticula von innen anliegt. Diese Röhre leuchtet am Rande stark auf, wird in der Mitte von einem dunklen Längsstreifen durchzogen und läuft an ihrem distalen Ende, an der Grenze gegen den fast isotropen Abschnitt, sich zuschärfend aus (vgl. Abb. 2). Das Verhalten des distalen Abschnittes soll erst später behandelt werden. Daß der doppelbrechende Hohlzylinder in seiner mittleren Längszone dunkel 
bleibt, erklärt sich aus radialer Lage der „optischen .Achse“, d. h. der Richtung, in der keine Doppelbrechung stattfindet. In der Mitte der Röhre erfolgt nun der Durchblick parallel der optischen Achse, so daß also Doppelbrechung fehlt. nach den beiden Rändern hin aber zunehmend schräg und schließłlich

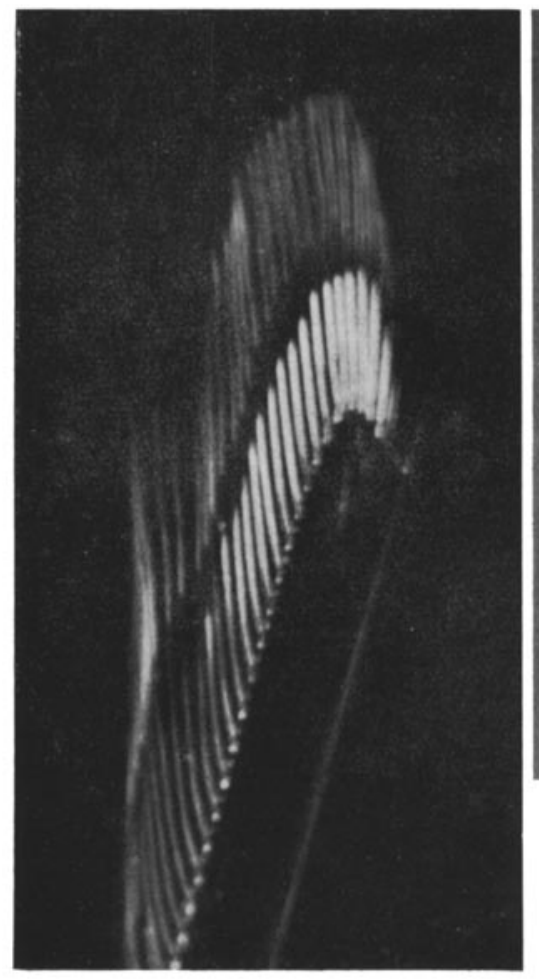

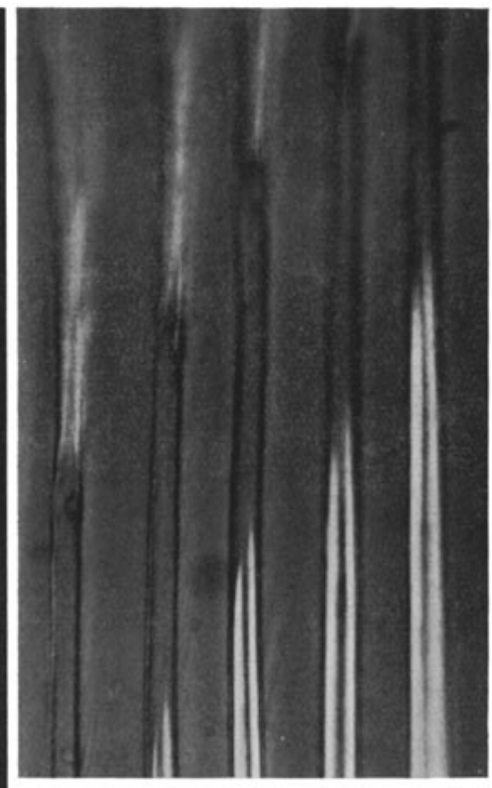

Abb. 2.

Abb. 1.

Abb. 1. Mysis, Schuppe der II. Antenne, frisch in Seewasser, Pol. $\chi, 42: 1$. Die proximalen Abschnitte der Borsten deutlich doppelbrechend, die mittleren kaum, die distalen merklich doppelbrechend.

Abb. 2. Mysis, Ausschnitt des Borstenbesatzes an der Schuppe der II. Antenne, frisch in Seewasser, Pol. $\times$, Brace-Köhler-Kompensator, 150:1, Ubergang des proximalen, deutlich doppelbrechenden Abschnittes (unten) über den fast isotropen zum schwach doppelbrechenden, distalen; im basalen Abschnitt der Borstenschäfte die doppelbrechende Röhre mit dunklem Mittelstreifen.

senkrecht dazu, wobei die Doppelbrechung bis zum Maximum ansteigt. So erinnert das Bild an die Optik der Markscheide einer Nervenfaser. Während jedoch in dieser das Vorzeichen der Doppelbrechung, bezogen auf die radiale optische Achse, positiv ist, verhält es sich hier negativ.

Es fragt sich nun, welcher morphologische Wert der doppelbrechenden Röhre zuzusprechen ist und aus welchem Material sie besteht. Man weiß (vgl. z. B. Zimmer 1926/27), daß solche befiederten Borsten bei Crustaceen Sinnesborsten sind, die von einer epidermal oder supepidermal gelegenen Sinneszelle (oder mehreren solchen) versorgt werden, indem diese eine Nervenfaser in die Borste entsendet. Diese (bei Mysis im frischen Zustande nicht sichtbare oder höchstens als undeutliche Längsstreifung wahrzunehmende) Faser wird also den Hohlraum der Röhre durchziehen. Manchmal (Abb. 3) treten in diesen von der Basis der Borste her noch Ausläufer von Chromatophoren ein, sowohl von schwarzen wie weißen (die letten mit doppelbrechenden Granulen). In den 
Borsten des letzten Abdominalbeinpaares fand ich nahe der Basis etwa ein Dutzend Zellkerne (in denen der Antennenschuppe aber waren Kerne nicht nachweisbar); die Bedeutung dieser Kerne blieb im Ungewissen.

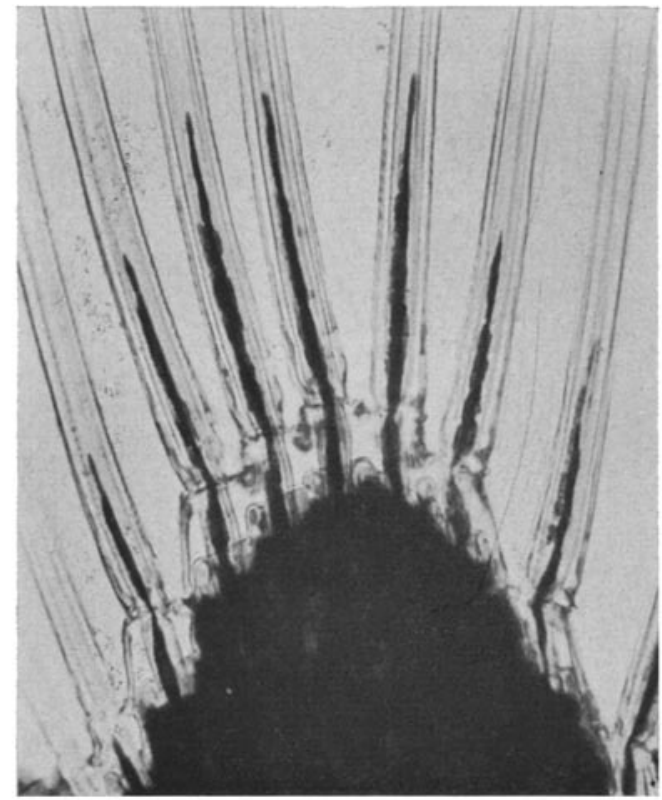

Abb. 3. Mysis, distales Ende der Schuppe der II. Antenne mit basalem Abschnitt der Borsten, fixiert mit Osmiumsäure, in Alkohol, 275:1. Eintreten von ChromatophorenFortsätzen in die Borsten.

Ihrer Lage nach Hülle einer Nervenfaser, könnte man die doppelbrechende Röhre einer "lokal ausgebildeten Markscheide" vergleichen. Mit dieser stimmt sie auch darin überein, daß sie - vermutlich neben Protein Lipoide enthält, wie sich nicht nur in ihrer allmählichen Bräunung unter Wirkung von Osmiumsäure ankündet, sondern auch darin, daß nach Zugabe von Alkohol die Röhre zu doppelbrechenden myelinfigurenartigen Gebilden sich wandelt (s. u.). Freilich darf der bereits oben erwähnte Unterschied des optischen Vorzeichens zwischen Markscheide und Röhre nicht aus dem Auge gelassen werden. Die zunächst naheliegende Erklärung, in der Röhre trete die gegensätgliche Doppelbrechung des Proteins infolge eines geringeren Gehaltes an Lipoid hervor (vgl. W. J. SснміDт, 1937 a), ist nicht im Einklang mit dem Umstande, daß die Röhre durch Behandlung mit Osmiumsäure an Stärke der Doppelbrechung abnimmt; wäre doch bei der versuchten Erklärung gerade das Gegenteil davon zu erwarten. Vielleicht ist sie auf die orientierte Einlagerung des doppelbrechenden, aber optisch gegensätzlich wirkenden Farbstoffes zu beziehen.

Der doppelbrechende Hohlzylinder im basalen Teil der Borste, der hier Träger der roten Farbe ist, zeigt im dunklen Sehfeld des Polarisationsmikroskops anomale, gelbrötliche bis gelbgrüne Polarisationsfarbe. Wo der Borste Farbstoff fehlt, tritt niemals ein solches Verhalten auf; in diesem Zusammenhang ist bemerkenswert, daß ich in einem Falle bei den Borsten der II. Antenne zwar die doppelbrechende Röhre wahrnahm, es mangelten aber die bezeichnende Färbung und die anomalen Polarisationsfarben. 
Versucht man im weißen Licht die Doppelbrechung der Röhre mit der drehbaren Glimmerplatte nach Brace-Köhler zu kompensieren, so tritt keine Schwärzung ein, wie es dem anomalen Charakter der Polarisationsfarbe entspricht. Vielmehr zeigt sich bei subtraktiver Drehung der Kompensatorplatte (d. h. wenn ein normales Objekt mit der großen Achse der Indexellipse unter $+45^{0}$ geschwärzt würde) Blau, im Gegensinne aber Gelb. Der Gebrauch von Farbfiltern lehrte, daß das Vorzeichen der Doppelbrechung für rotes und grünes Licht positiv ist; für Blau besteht sehr schwache Doppelbrechung bei anscheinend negativem Vorzeichen. Wenn also im weißen Licht für Rot und Grün kompensiert wird, zeigt sich als Polarisationsfarbe das nicht kompensierte Blau, und wenn durch gegensätgliche Drehung Blau kompensiert wird, erscheint das komplementäre Gelb. Diese Erscheinungen bei Betätigung des Kompensators sind sehr auffallend und verraten die Anwesenheit des Farbstoffes nachdrücklich sogar da, wo er im gewöhnlichen Licht kaum sichtbar ist.

Weiter zeigt die doppelbrechende Röhre Dichroismus, erscheint, über dem Polarisator allein beobachtet, parallel zu dessen Schwingungsrichtung bräunlich-rot, senkrecht dazu farblos. Dichroismus an roten Borsten bei Crustaceen, z. B. beim Hummer, hat bereits Ambronn (1892) gesehen (vgl. auch W. J. SснміDт, 1937 b).

Die geschilderten Erscheinungen - die Doppelbrechung mit anomalen Polarisationsfarben und der Dichroismus - gehen also mit der Anwesenheit des Farbstoffes Hand in Hand, werden von ihm hervorgerufen. Damit sie eintreten können, muß aber der Farbstoff selbst doppelbrechend und dichroitisch und feinbaulich geordnet sein: das lette hat aber zur Voraussetzung, daß das Material, in dem er liegt, orientierten Feinbau besityt.

Die gleichen optischen Verhältnisse kehren im distalen Abschnitt der Borste wieder. Hier findet sich der Farbstoff in den außerordentlichen feinen Haaren, welche die Borsten befiedern. Sie zeigen die gleichen anomalen (im Exo- und Fndopoditen des leţten abdominalen Beinpaares auch bläulichen) Polarisationsfarben, wie sie für den Borstenschaft geschildert wurden, dieselben anomalen Erscheinungen bei der Kompensation und schließlich den Dichroismus rot-farblos; ja, all dies ist hier noch schöner zu beobachten als an den Borstenschäften.

Die morphologischen Verhältnisse der Haare freilich lassen sich bei ihrer großen Feinheit sehr viel schwieriger erkunden. Man wird aber angesichts der Übereinstimmung der optischen Erscheinungen und noch weiter unten zu nennender Tatsachen annehmen dürfen, daß, wie im Borstenschaft, auch in der Achse der Haare ein lipoidhaltiges, feinbaulich geordnetes Material sich befindet, in das der Farbstoff orientiert eingelagert ist. $\mathrm{Ob}$ allerdings in dieser Masse ein Hohlraum sich befindet, dem Lumen der Röhre im Borstenschaft vergleichbar, und ob dieser etwa von Abzweigungen der Nervenfaser durchzogen wird, muß dahingestellt bleiben.

Setzt man nun zu einer in Seewasser unter Deckglas befindlichen Schuppe der II. Antenne oder einem der leţten Abdominalfüße 95\% oigen Alkohol zu (ich benutzte Isopropylalkohol), dann vollzieht sich ein überraschender Vorgang: Sogleich verlieren die gefärbten Teile der Borste ihre Tönung und im Polarisationsmikroskop gewahrt man, wie die anomalen Polarisationsfarben verlöschen, der dunkle Mittelstreifen der doppelbrechenden Röhre verschwindet und diese zu einer unregelmäßig geformten, doppelbrechenden, an Myelinfiguren erinnernden Masse zusammenfließt. Zugleich treten schlagartig an den 
ehemals gefärbten Stellen zahllose ziegelrote Kristalle auf. Sie sind stark doppelbrechend, bieten dieselben anomalen (gelblichen bis rötlichen) Polarisationsfarben und den gleichen Dichroismus dar, wie er für den natürlichen Zustand der gefärbten Teile geschildert wurde. Zunächst zeigen sie sich am distalen Borstenende in den Haaren; ihre Bildung schreitet sogleich proximalwärts fort und schließlich erscheinen sie auch im Borstenschaft vor allem in dem Bereich, der ehemals der doppelbrechenden Röhre zukam.

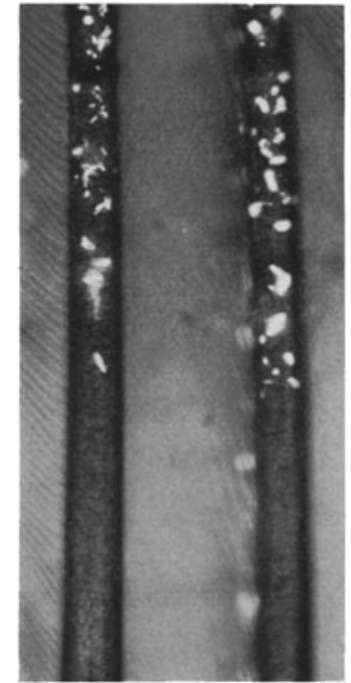

Abb. 4.

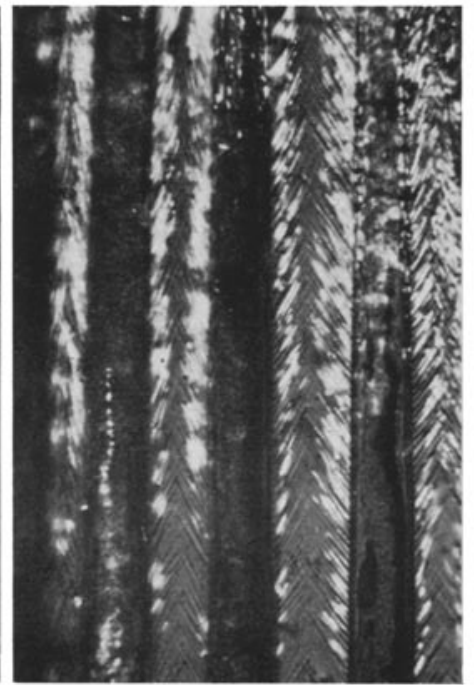

Abb. 5.

Abb. 4. Mysis, distaler Abschnitt der Borsten an der Schuppe der II. Antenne, frisch in Seewasser unter Deckglas, mit Alkohol behandelt; Pol. $X, 375: 1$. Rote doppelbrechende Kristalle in den Haaren der Borsten.

Abb.5. Mysis, basaler Abschnitt der Borsten an der Schuppe der II. Antenne, frisch, in Seewasser unter Deckglas, nach Zusatz von Alkohol; Pol. X, Brace-Köhler-Kompensator, $375: 1$. Rote doppelbrechende Kristalle in den Borstenschäften.

In den Haaren (Abb. 4) besitzen die Kristalle strichartige Gestalt, liegen in einfacher Reihe hintereinander in der Haarachse; ja, manchmal ist diese von einem einzigen derartigen Gebilde erfüllt. Die Anwesenheit der Kristalle in der Haarachse und ihre strichartige Form bezeugen, daß der cuticulare Überzug der Haare ein röhrenförmiges, sonst schwer nachweisbares Lumen umschließt, das die Gestalt des Kristallisates bestimmt. Diese Kristalle löschen der Länge nach aus und verhalten sich fast ausnahmslos positiv zu dieser Richtung; ihrer längsverlaufenden Schwingungsrichtung ist die starke Absorption zugeordnet. Wo aber ehemals die doppelbrechende Röhre lag, treten die Kristalle im Lumen des Borstenschaftes auf; hier zeigen sie nicht nur stäbige Form, sondern manchmal auch quadratischen oder rechteckigen Umriß. (Abb. 5).

Die geschilderten Vorgänge bei Zusat von Alkohol spielen sich mit größter Regelmäßigkeit $a b$, wie ich mich in dutzendfachen Versuchen überzeugen konnte. Überschuß von Alkohol löst die Kristalle auf.

Offenbar tritt durch den Alkohol Zerstörung der farbtragenden Grundlage ein, die gewiß an ihrem lipoiden Bestandteil ansetzt; und damit kommt 
es zur Kristallisation. Ob freilich die Kristalle aus reinem Farbstoff bestehen, oder ob sie nicht Komplexe von Farbstoff und Liopid darstellen, etwa in der Art, daß der Farbstoff mit diesem verestert vorliegt (s. u.), vermag ich nicht zu entscheiden. Die auffallend große Menge der Kristalle im Vergleich zu der schwachen Färbung des Materials im natürlichen Zustand, insbesondere aber die Tatsache, daß einzelne Borsten ganz von der kristallinen Masse erfüllt erscheinen, spricht wohl mehr im letzten Sinne.

Durch Untersuchungen neuerer Zeit (s. Kunn, Stene \& Sörensen, 1939) ist sichergestellt, daß der rote Farbstoff in der Hypodermis des Hummers ein Abkömmling des Carotins, ein doppeltes Ketol desselben ist, Astaxanthin genannt. Dieses findet sich in der roten Epidermis in Form von Fettsäureestern, im blauschwarzen Panzer (und in den grünen Eiern) aber als doppeltes Dienol an Protein gebunden. Durch Einwirken von Alkali und Zutritt von Luft geht Astaxanthin in das Tetraketon Astacin über, das im Organismus nur als Kunstprodukt aufzutreten scheint. Astaxanthin (oder sein Oxydationsprodukt Astacin) wurde bei zahlreichen Crustaceen nachgewiesen, unter den Schizopoden bei Euphausia. LönNBerg \& Hallström (1931) erhielten aus Mysis flexuosa einen gelben Methylalkoholextrakt, in dem spektroskopisch carotinoide Stoffe sich nachweisen ließen.

So wird man auch den roten Farbstoff bei Mysis als Astaxanthin betrachten dürfen und annehmen können, daß er da, wo er rot erscheint (II. Antenne) mit fettartigen Stoffen verestert ist; der bläuliche Farbton in den letten Abdominalbeinen aber scheint darauf hinzuweisen, daß hier auch Bindung an Protein besteht.

Nach Abschluß dieser Untersuchung stieß ich zufällig auf die Angaben von E. Bünning (1937; 1938), der bei Pilobolus beobachtete, daß bei Zugabe von Athyl-oder Methylalkohol in wenigen Sekunden das Carotin auskristallisierte, so daß also auch bei einem pflanzlichen Objekt hinsichtlich der Bildungsbedingungen der Kristalle ähnliche Beobachtungen gemacht wurden.

Dem Farbstoff bei Mysis wird man wohl kaum eine spezifische physiologische Bedeutung zuschreiben wollen; vielmehr liegt die Vorstellung nahe, daß er als Carotin mit der Nahrung in das Tier hineingelangt, resorbiert und umgebaut wird und dann dort zur Ablagerung kommt, wo die Bedingungen für seine Speicherung am günstigsten sind. Daß aber in den äußerst feinen Haaren der Borsten durch die Anwesenheit des Farbstoffes das ihn tragende Lipoid sich nachweisen läßt, ist deshalb nicht ohne Interesse, weil nach neueren Auffassungen Lipoide bei der Erregungsleitung im Nerven eine wesentliche, wenn auch im einzelnen noch nicht durchschaute Rolle spielen.

\section{Zusammenfassung}

Die Sinnesborsten der Schuppe der II. Antenne und des leţten Abdominalbeinpaares von Mysis flexuosa zeigen rötliche beziehungsweise rotviolette Färbung. Diese gehört einerseits, nämlich im basalen Teil der Borste, einer röhrenartig innen der Cuticula des Borstenschaftes anliegenden, lipoidhaltigen Masse zu, die doppelbrechend ist, und zwar mit radialer, negativer optischer Achse; andererseits aber, und zwar im distalen Abschnitt der Borsten, sind die feinen Haare, welche die Borsten beidseitig befiedern, gefärbt, und zwar befindet sich die farbtragende Masse in ihrem fadenförmigen Lumen. Wo 
Färbung vorliegt, und nur da, zeigen sich anomale Polarisationsfarben, bei Betätigung der drehbaren Glimmerplatte nach Brace-Köhler anomale Kompensationserscheinungen und weiter Dichroismus (Rot-Farblos), Erscheinungen, die den Farbstoff viel deutlicher verraten, als die direkte Beobachtung.

Setzt man den genannten, in Seewasser unter Deckglas liegenden Teilen der Mysis Alkohol (Isopropylalkohol wurde benutst) zu, so fallen an den gefärbten Teilen, und zwar in ihrem Innern, massenhaft rote, stark doppelbrechende Kristalle aus. Diese zeigen die gleichen optischen Eigenschaften, wie sie für die betreffenden Abschnitte der Borsten bzw. ihrer Haare im natürlichen Zustande oben angegeben wurden. Der Farbstoff, der als Astaxanthin gelten kann, ist gemäß den geschilderten optischen Erscheinungen am natürlichen Objekt orientiert einer lipoidhaltigen Grundmasse eingelagert.

\section{Schriftum}

Ambronn, H. 1892: Anleitung zur Benutzung des Polarisationsmikroskops bei histologischen Untersuchungen, Leipzig 1892.

Bünning, A. 1937: Phototropismus und Carotinoide I. Phototropische Wirksamkeit von Strahlen verschiedener Wellenlänge und Strahlungsabsorption im Pigment bei Pilobolus. Planta 26, 716-736.

Bünning, A. 1938: Phototropismus und Carotinoide II. Das Carotin der Reizaufnahmezone von Pilobolus, Phycomyces und Avena. Planta 27, 148-158.

Kuhn, R. J. Stene \& N. A. Sörensen 1939: Über die Verbreitung des Astaxanthins in Tier- und Pflanzenreich. Ber. chem. Ges, 72, 1688-1701.

E. Lönnberg \& H. Hallström 1931: Zur Kenntnis der Carotinoide bei marinen Evertebraten. Ark. Zool. 23 A, No. 15, 1-74.

Schmidt, W. J. 1937 a: Die Doppelbrechung von Karyoplasma, Zytoplasma und Metaplasma. Protoplasmamonographie 11, Berlin.

Schmidt, W. J. 1937 b: Über natürlichen Dichroismus tierischer Gewebe. Z.Mikr. 54, $379-389$

Zimmer, C. 1926/27: Grustacea, in Kükenthal's Handbuch der Zoologie. Bd. III, 1, 277 bis 304 und $607-650$. 